\title{
Brain metastasis in HER2 positive stomach cancer
}

\author{
Yasemin Benderli Cihan* \\ Kayseri City Hospital, Department of Radiation Oncology, Turkey
}

\section{Brain metastasis in HER2 positive stomach cancer}

Stomach cancer is seen in 7-8\% of cancers worldwide. Although its incidence has decreased gradually in the last fifteen years, it is among the most common causes of cancer-related deaths. Most stomach adenocarcinomas are still diagnosed at advanced stages, despite improvements in diagnostic methods. The survival rate is very low, as most cases are diagnosed at an advanced stage, aggressive behavior and limited treatment options. Five-year survival is $85-100 \%$ in early stomach cancer and 5-20\% in advanced stomach cancer [1-3]. For this reason, many years of intense studies are underway to investigate etiological causes, to make early diagnosis, to determine predictive and prognostic factors in treatment, and to develop the treatment methods applied. It is seen that the results of large case series for treatment and prognosis in the literature show significant differences. In fact, significant prognosis differences between patients who are in the same stage and have clinically similar features show that gastric cancer has a biologically heterogeneous group. Therefore, it is important to investigate new determining factors other than known predictive and prognostic factors (tumor histological type, depth of invasion, lymph node involvement, distant metastasis).

Today, thanks to genetic analysis and molecular studies, the role of some genes in gastric carcinogenesis has been determined [2]. One of these genes is the epidermal growth factor receptor-2 (HER-2/neu/ c-erbB2) gene, located on chromosome 17q. This is a member of the HER family and a protooncogene. HER 2 acts by increasing tyrosine kinase activity. As a result, cell proliferation, angiogenesis increases, and apoptosis is suppressed. HER2 is not tissue-specific and is found in various tissues such as breast, colon, lung, ovary and kidney. HER-2/ neu expression has been investigated in cancers seen in these tissues. However, studies showing the importance of increased expression of this protein are concentrated especially in breast and stomach carcinomas [2-4].

The importance of HER-2/neu gene in breast cancer after breast cancer has become more and more important. However, evaluation of HER-2/neu expression in stomach cancer is more difficult and complicated than breast cancer. In different studies, approximately 15$20 \%$ of the cases had over-expression of HER- 2 protein. In the literature, besides studies reporting that HER 2 overexpression is associated with more aggressive behavior and poor prognosis, there are also studies in the literature that suggest a slightly positive prognostic factor. In most studies, HER2 overexpression has been reported to be associated with serosal invasion, lymph node metastasis, stage, and distant metastasis [1-6].

It is known that especially combined chemotherapeutic agents increase overall survival compared to single agents in stomach cancer. Although many chemotherapy regimens were tested in randomized studies, the internationally accepted standard treatment and chemotherapy regimen could not be determined. For these reasons, new treatment approaches were needed [2]. He raised the question of the extent to which humanized monoclonol antibodies (such as lapatinib, trastuzumab, imtansine and pertuzumab) can be successful in treatment in gastric carcinomas showing HER-2/neu expression. Anti-HER2 monoclonal antibody (trastuzumab) has been shown to inhibit the growth of gastric cancer cells in vitro and in vivo. This effect shows that the combination of trastuzumab with chemotherapy will have a positive effect on treatment. In studies conducted, it was reported that the average survival increased from 11.1 months to 13.8 months in combination with chemotherapy applied to the basta with transtuzumab [5]. In the Phase 3 randomized ToGA study; The rate of HER-2 overexpression in gastric cancer was $22 \%$. With the addition of trastuzumab to the standard chemotherapy regimen in these patients, it was shown that the response rates and overall survival time increased compared to the group receiving chemotherapy alone [4]. With the results of this study, it caused trastuzumab to be used as a new treatment option in stomach cancer treatment.

Although HER2-positive breast cancers tend to metastasize to the central nervous system, it is not clear whether HER 2-positive stomach cancers have this feature. Stomach cancer usually metastasizes to the liver, peritoneal cavity and lymph nodes. It rarely metastasizes to the brain and is usually seen at $2 \%$. In studies conducted, it was reported that central nervous system metastases were higher and relapsed more frequently in both positive gastric cancers. Due to these features, prognosis is poor in cases with brain metastasis [7-11]. In treatment, local treatment options (neurosurgery, radiosurgery and radiotherapy and symptomatic treatment with steroids) are applied. Features all brain radiotherapy is preferred in these cases. Stereotactic radiotherapy is known to have a positive effect on overall survival, especially in patients who develop relapse after brain metastasis treatment $[10,11]$. It is not known according to current information that other HER2-targeted therapies except trastuzumab can positively change the prognosis of these patients and prolong the involvement of the brain and meninges.

As a result, efforts are made to identify biomarkers to predict survival or relapse in stomach cancer. HER-2 neu proto-oncogene plays a role in pathogenesis and progression in many tumors, especially stomach cancer. It is recommended that all patients diagnosed with HER2 gastric cancer should be looked after. However, the prognostic significance of Her-2/neu positivity in brain metastasis remains controversial. Studies are needed to improve the combined use of local and HER2 targeted therapies in patients with brain metastases.

${ }^{*}$ Correspondence to: Yasemin Benderli Cihan, Kayseri City Hospital, Department of Radiation Oncology, Şeker District, Muhsinyazıcıoğlu Boulevard, No:77, 38080, Kocasinan/Kayseri, Turkey, Tel +90 3523157700 - 01 - 02; Fax +90 35231579 86; H/P: +90 536216 9987; E-mail: cihany@erciyes.edu.tr

Received: May 05, 2020; Accepted: May 11, 2020; Published: May 15, 2020 


\section{References}

1. Baumgartner R, Taghizadeh H, Jomrich G, Schoppmann SF, Preusser M, et al. (2020) Utilization and efficacy of palliative chemotherapy for locally advanced or metastatic gastroesophageal carcinoma. Anticancer Res 40: 965-975. [Crossref]

2. van den Ende T, Smyth E, Hulshof MCCM, van Laarhoven HWM (2018) Chemotherapy and novel targeted therapies for operable esophageal and gastroesophageal functional cancer. Best Pract Res Clin Gastroenterol 36: 45-52. [Crossref]

3. Zaanan A, Bouché O, Benhaim L, Buecher B, Chapelle N, et al. (2018) Gastric cancer: French intergroup clinical practice guidelines for diagnosis, treatments and follow-up. Dig Liver Dis 50: 768-779. [Crossref]

4. Bang YJ, Van Cutsem E, Feyereislova A, Chung HC, Shen L, et al. (2010) Trastuzumab in combination with chemotherapy versus chemotherapy alone for treatment of HER2positive advanced gastric or gastro-oesophageal junction cancer (ToGA): a phase 3 , open-label, randomised controlled trial. Lancet 376: 687-697. [Crossref]

5. Bang Y, Chung H, Xu J, Lordick F, Sawaki A, et al. (2009) Pathological features of advanced gastric cancer (GC): relationship to human epidermal growth factor receptor 2 (HER2) positivity in the global screening programme of the ToGA trial. J Clin Oncol 27: $1-10$.
6. Müller V, Clemens M, Jassem J, Al-Sakaff N, Auclair P, et al. (2018) Long-term trastuzumab (Herceptin $\left.{ }^{\circledR}\right)$ treatment in a continuation study of patients with HER2positive breast cancer or HER2-positive gastric cancer. BMC Cancer 18: 295 [Crossref]

7. Ghidini M, Petrelli F, Hahne JC, De Giorgi A, Toppo L, et al. (2017) Clinical outcome and molecular characterization of brain metastases from esophageal and gastric cancer: a systematic review. Med Oncol 34: 62. [Crossref]

8. Feilchenfeldt J, Varga Z, Siano M, Grabsch HI, Held U, et al. (2015) Brain metastase in gastro-oesophageal adenocarcinoma: insights into the role of the human epidermal growth factor receptor 2 (HER2). Br J Cancer 113: 1747. [Crossref]

9. Blay C, Chiforeanu DC, Boucher E, Cabillic F, Desgrippes R, et al. (2015) Incidence of brain metastases in HER2+ gastric or gastroesophageal junction adenocarcinoma. Acta Oncol 54: 1833-1835. [Crossref]

10. Yoon HH, Lewis MA, Foster NR, Sukov WR, Khan M, et al. (2016) Central nervous system relapse in patients with untreated HER2-positive esophageal or gastroesophageal junction adenocarcinoma. Int J Cancer 139: 1626-1631. [Crossref]

11. Preusser M, Berghoff AS, Ilhan-Mutlu A, Dinhof C, Magerle M, et al. (2013) Brain metastases of gastro-oesophageal cancer: evaluation of molecules with relevance for targeted therapies. Anticancer Res 33: 1065-1071. [Crossref]

Copyright: $(02020$ Cihan YB. This is an open-access article distributed under the terms of the Creative Commons Attribution License, which permits unrestricted use, distribution, and reproduction in any medium, provided the original author and source are credited. 